\title{
Repercusión de Lactobacillus acidophilus y Kluyveromyces fragilis (L-4 UCLV) en los parámetros bioproductivos de los cerdos
}

\section{(Repercution of Lactobacillus acidophilus and Kluyveromyces fragilis (L-4UCLV) on the bioproductive parameters of pigs)}

\author{
JE Miranda-Yuquilema ${ }^{1,2}$, A Marin-Cárdenas², M González-Pérez ${ }^{3}$, A Valla-Cepeda ${ }^{4}$, D \\ Baño-Ayala ${ }^{4}$
}

\begin{abstract}
Resumen:
Con el objetivo de evaluar la repercusión de Lactobacillus acidophilus y Kluyveromyces fragilis (L-4UCLV) sobre los indicadores productivos y de la salud de los cerdos en las diferentes etapas productivas, se realizaron dos experimentos (I y II). Se emplearon 14 y 45 cerdos híbridos CC21 (Yorkshire - Landrace/ L35 Duroc), respectivamente, distribuidos en dos y tres grupos de 7 y 15 animales cada uno. Control (T1); preparadoA (T2) y preparado-B (T3). T2, contenía $L$. acidophillus y T3, L. acidophilus más $K$. fragilis (L-4 UCLV). Se utilizó un diseño completamente aleatorizado donde se evaluó ganancia de peso (GP), ganancia media diaria (GMD), conversión alimenticia (CA), eficiencia alimenticia (EA), incidencia de diarreas y mortalidad. La GP, GMD, CA y EA fue mayor ( $p>0.05)$ en el T2 (21.4 kg, $535 \mathrm{~g}, 1.83$ y $57.3 \%$ ) en el experimento I y en T3 $(54.29 \mathrm{~kg}, 775 \mathrm{~g}, 49.8 \%)$ en el segundo. La incidencia de diarreas y porcentaje de mortalidad fue menor $(p<0.05)$ en tratamientos T2 y T3. En conclusión, con el uso de preparados probióticos se mejoran los parámetros productivos y se logra reducir la incidencia de diarreas y mortalidad en todas las etapas estudiadas.
\end{abstract}

Palabras clave: probióticos; producción porcina; subproductos de la agroindustria.

\begin{abstract}
:
With the objective of evaluating the repercussion of Lactobacillus acidophilus and Kluyveromyces fragilis L-4UCLV on the productive indicators and the health of the pigs in the different productive stages, two experiments (I and II) were carried out. 14 and 42 hybrid pigs CC21 (Yorkshire - Landrace / L35 Duroc) were used, respectively, distributed in two and three groups of 7 and 14 animals each. Control (T1); prepared-A (T2) and prepared-B (T3). T2, contained L. acidophillus and T3, L. acidophilus more $K$. fragilis (L-4 UCLV). A completely randomized design was used to evaluate weight gain (WG), average daily gain (ADG), feed conversion (FC), food efficiency (FE), incidence of diarrhea and mortality. WG, ADG, FC and FE were higher $(p<0.05)$ in T2 in experiment $I$ and in T3 in the second. The incidence of diarrhea and the percentage of mortality was lower $(p<0.05)$ in T2 and T3. In conclusion, with the use of probiotic preparations, the productive parameters are improved and the incidence of diarrhea and mortality in all the stages studied is reduced.
\end{abstract}

Keywords: probiotics; swine production; agroindustrial waste.

\footnotetext{
${ }^{1}$ Becario del Instituto de Fomento a Talento, SENESCYT, Ecuador (efra_miranda@outlook.com)

2 Universidad Central "Marta Abreu" de Las Villas, Santa Clara, Cuba.

${ }^{3}$ Centro de Investigaciones Agropecuarias (CIAP-UCLV), Santa Clara, Cuba.

${ }^{4}$ Escuela Superior Politécnica de Chimborazo, Riobamba, Ecuador.
} 


\section{Introducción}

A finales del siglo pasado el empleo de antibióticos promotores de crecimiento fue una alternativa para mejorar la producción animal; sin embargo, por los efectos adversos de estas sustancias en la salud del ser humano, las investigaciones buscan alternativas para sustituirlas (Miranda et al., 2017). Los microorganismos con capacidad probiótica podrían ser una opción para equilibrar la microbiota natural del huésped, sin que estos provoquen efectos adversos (Ciro et al., 2015). Los cultivos microbianos usados en la producción porcina reducen o eliminan los patógenos en el tracto gastrointestinal, así como residuos de antibióticos y otras sustancias análogas, además de mejorar la salud y el comportamiento productivo, al reducir la incidencia de diarreas y muertes (Campbell et al., 2013).

El efecto de los probióticos empleados en la dieta porcina dependerá de los microorganismos utilizados, debido a que no todos los organismos tienen la capacidad de modular la microbiota natural del sistema intestinal o de adherirse a las células intestinales (Farzan et al., 2013). En la actualidad, numerosos países muestran mayor interés por estudiar los mecanismos para mejorar la salud y reducir la muerte en la etapa de destete y posdestete. Los principales factores que han incidido en la mayor pérdida de los lechones en este período se deben a la separación abrupta de sus madres y la reagrupación con animales provenientes de otras camadas con un ambiente diferente al que llegan; todo lo anterior se desprende por el estrés ambiental que conduce a una inmunodepresión; esta situación es crítica por ser un momento crucial en el desarrollo fisiológico postnatal del cerdito (Liu et al., 2013, FAO, 2016).

Mediante la acción antimicrobiana, variación de $\mathrm{pH}$ y la producción de ácidos grasos de cadena corta, principalmente láctico, se crea un ambiente inhostil para los agentes patógenos. Dicha acción favorece en la prevención de enfermedades infecciosas en los cerdos, al disminuir los índices de morbilidad y mortalidad en las crías; aumentan el rendimiento bioproductivo y mejoran el bienestar en el hospedador para así permitir que el ser humano se pueda beneficiar de sus productos finales que son amigables con el medio ambiente (Campbell et al., 2013; Farzan et al., 2013). Diversos países europeos y de América Latina, estudian los efectos de los probióticos en algunas especies animales, a saber, en ganado bovino, porcino, canícula, ovino y aves. (Pajarilla et al., 2014). Si se tiene en cuenta todo lo anterior, el presente estudio tuvo como objetivo evaluar el efecto probiótico de las bacterias y levaduras en los indicadores productivos, control de diarreicos y muertes de cerdos en las etapas de crecimiento, preceba e inicio de ceba.

\section{Materiales y métodos}

Área de estudio: los trabajos experimentales se realizaron en el Laboratorio de fermentaciones y Laboratorio de bromatología, Centro de Investigaciones Agropecuarias (CIAP), Laboratorio de microbiología, Facultad de Ciencias Agropecuarias y en la estación experimental zootécnica, Universidad Central "Marta Abreu" de Las Villas, Santa Clara, ubicada $22^{\circ} 09^{\prime} 00^{\prime \prime} \mathrm{N} 79^{\circ} 58^{\prime} 35^{\prime \prime} \mathrm{O}$, altitud 350 metros sobre nivel de mar, precipitación anual: $115 \mathrm{~mm}$, temperatura media $24.2 \stackrel{\circ}{\circ}$ y humedad relativa anual $82.97 \%$.

Diseño y tratamientos experimentales: se utilizó un diseño completamente aleatorizado. Experimento I, estaba conformado por dos grupos de siete animales. Experimento II, se utilizaron 45 animales en total, distribuidos en tres grupos de 15 animales, donde cada cerdo representaba una unidad experimental. Los tratamientos evaluados fueron: control (T1); aditivo microbiano A (T2) y aditivo microbiano B (T3).

Animales y dieta basal: Experimento I: se emplearon 14 lechones destetados (33 días de edad) híbridos CC21 (Yorkshire - Landrace / L35 Duroc), 7 machos en igual cantidad de hembras, con peso promedio de $9 \pm 2 \mathrm{Kg}$. Experimento II: se utilizaron 45 cerdos en la categoría crecimiento CC21 (Yorkshire - Landrace/ L35 Duroc), 21 machos y 21 hembras, con peso promedio, $13 \pm 2$, edad $45 \pm 2$ días. Los lechones del primer estudio 
(siete animales) fueron alojados en corrales colectivos de $2 \times 2.5 \mathrm{~m}$ y piso de cemento. En el segundo experimento, los 15 cerdos fueron ubicados en corrales de $6 \times 6.5 \mathrm{~m}$ pisos de cemento. El alimento empleado en el experimento I, contenía: $95.2 \%$ Materia Seca (MS); 18.6 Proteína Bruta (PB); $3.4 \%$ Fibra Bruta (FB) y 4.2\% Ceniza (Cz), y para el II estuvo compuesto por $92.4 \% \mathrm{MS}$; $16.5 \mathrm{~PB}$; $3.6 \% \mathrm{FB}$ y $4.1 \% \mathrm{Cz}$, cumpliendo con los requerimientos mínimos recomendados por el NRC (2012). El alimento se ofreció dos veces por día, a las 7:00 a.m. y 4:00 p.m. El agua se suministró ad libitum en bebederos tipo tetinas.

Sistemas de manejo y condiciones experimentales: en los dos experimentos todos los animales fueron sometidos a iguales condiciones de manejo. Se mantuvo la temperatura ambiente del cuartón a $23^{\circ} \mathrm{C}$ durante el experimento. El fotoperíodo fue controlado con 14 horas de luz y 10 horas de oscuridad. Así mismo se garantizó una adecuada ventilación en los cuartones. Los animales de cada grupo se ubicaron distantes unos de otros (con un cuartón intermedio o a ambos lados del pasillo) para evitar la auto inoculación.

Preparados microbianos: las cepas utilizadas en los preparados microbianos fueron Lactobacillus acidophilus, proveniente del banco de cepas Villa Clara (Cuba) y Kluyveromyces fragilis (L-4 UCLV) del banco de cepas de la Universidad Central "Marta Abreu" de Las Villas (Cuba). Estas se activaron en leche descremada a $37^{\circ} \mathrm{C}$ por $24 \mathrm{~h}$. Para la obtención de los preparados microbianos se utilizó como sustrato $30 \%$ de melaza de caña de azúcar y $58 \%$ de leche de soja, homogenizado a $150 \mathrm{rpm}$ durante 10 minutos, y se fermentó a $37^{\circ} \mathrm{C}$ por 24 h, según la metodología descrita por Miranda et al. (2017). El preparado A contenía $L$. acidophilus y el preparado B estuvo compuesto por las bacterias del preparado-A más $K$. fragilis (L-4 UCLV). La composición química y la concentración microbiana de cada preparado se presentan en la Tabla 1.

Tabla 1. Composición de los preparados microbianos a incluir en la dieta basal de los cerdos durante el estudio

\begin{tabular}{|c|c|c|}
\hline \multirow[b]{2}{*}{ Indicadores } & \multicolumn{2}{|c|}{ Preparados microbianos } \\
\hline & $\begin{array}{l}\text { Preparado-A } \\
\text { (T2) }\end{array}$ & $\begin{array}{l}\text { Preparado-B } \\
\text { (T3) }\end{array}$ \\
\hline Materia seca, \% & 35.5 & 34.5 \\
\hline Proteína cruda, \% & 16.2 & 17.1 \\
\hline $\begin{array}{l}\text { Proteína verdadera, \% } \\
\text { Extracto etéreo, \% }\end{array}$ & $\begin{array}{c}8.3 \\
2.52\end{array}$ & $\begin{array}{c}9.1 \\
2.32\end{array}$ \\
\hline Cenizas, \% & 2.82 & 2.16 \\
\hline $\mathrm{pH}$ & 3.88 & 3.85 \\
\hline Ácido láctico, $\mathrm{mmol} / \mathrm{mL}$ & 0.72 & 0.72 \\
\hline $\begin{array}{l}\text { Concentración } \\
\text { microbiana, UFC/mL }\end{array}$ & $8.2 \times 10^{7}$ & $9.1 \times 10^{8}$ \\
\hline
\end{tabular}

Empleo de los aditivos microbianos a los animales en estudio: los aditivos microbianos se aplicaron a las 7:00 a.m., cada tres días en los dos estudios. Los animales del grupo T2 en la experiencia I, consumieron $3 \mathrm{~mL}$ de aditivo, el cual se proporcionó al mezclarlo en $100 \mathrm{~g}$ de la dieta basal y $50 \mathrm{~mL}$ agua, a partir del destete hasta 52 días de edad. En el segundo experimento, la primera dosis aplicada fue en monodosis a los 45 días de edad, independientemente del grupo asignado. La dosificación, en forma oral, varió de acuerdo con la edad: $3 \mathrm{~mL}$ en el primer mes; $4 \mathrm{~mL}$ en el segundo y partir de ahí $5 \mathrm{~mL}$ hasta los 115 días de edad. Los animales del grupo control recibieron suero fisiológico en igual cantidad que los grupos tratados. 


\subsection{Variables de respuesta}

Pesaje Peso y cálculo de los indicadores productivos: el pesaje a los animales en el estudio I, se realizó al inicio (33 días de edad) y cada 15 días, mientras que los cerdos del segundo experimento se pesaron en un intervalo de 20 días; para el mismo se utilizaron dos básculas romanas (URKO) de 50 (experimento I) y 75 (experimento II) $\mathrm{Kg}$, previamente calibradas con un error $\pm 0.50 \mathrm{~g}$. Con esta información, se calculó la ganancia de peso (GP), ganancia media diaria (GMD), conversión alimenticia (CA), eficiencia alimenticia (EA), incidencia de diarreas y mortalidad de los animales. Los experimentos I y II tuvieron una duración de 40 y 70 días, respectivamente.

Control de diarreas y mortalidad: los animales fueron sometidos a un riguroso control clínico para detectar cambios de conducta y/o trastornos diarreicos, lográndose analizar a cada animal individualmente, pues estaban identificados y fueron registrados diariamente.

Análisis estadístico: las variables utilizadas fueron comportamiento de peso, ganancia de peso, ganancia media diaria, conversión alimenticia y eficiencia alimenticia. El análisis fue realizado mediante la aplicación de un modelo de análisis de varianza simple, previa comprobación de la distribución normal de los datos y de la homogeneidad de varianza. Donde existió diferencia estadística significativa se aplicó la prueba de Duncan (1955). Todas las pruebas fueron realizadas mediante los paquetes estadísticos Statgraphics plus 15.1 para Windows.

\section{Resultados}

\subsection{Experimento I}

En la Tabla 2 se reporta el comportamiento productivo de los lechones que consumieron aditivo microbiano a partir del destete hasta 73 días de edad. En las mediciones realizadas con 48 y 63 días de edad, la ganancia de peso y ganancia media diaria fueron mayores $(p<0.05)$ en los lechones que consumieron el preparado microbiano con respecto a T1.

Tabla 2. Comportamiento productivo de los lechones que consumieron preparado microbiano, en el experimento I

\begin{tabular}{|c|c|c|c|c|c|}
\hline \multirow{2}{*}{ Edad, $\mathbf{d}$} & \multirow{2}{*}{ Indicadores } & \multicolumn{2}{|c|}{ Tratamientos } & \multirow{2}{*}{ SEM } & \multirow{2}{*}{ valor-P } \\
\hline & & T1 & T2 & & \\
\hline \multirow{2}{*}{ Inicio (33 d) } & $\mathrm{PV}, \mathrm{kg}$ & 9.50 & 9.45 & 0.21 & 1.1202 \\
\hline & $\mathrm{GP}, \mathrm{kg}$ & $5.15^{b}$ & $6.70^{\mathrm{a}}$ & 0.13 & 0.0241 \\
\hline \multirow{4}{*}{$33-48$} & GMD, g & $343^{b}$ & $446^{a}$ & 0.10 & 0.0011 \\
\hline & CA & $2.14^{\mathrm{a}}$ & $1.64^{b}$ & 0.01 & 0.0012 \\
\hline & $\mathrm{EA}, \%$ & 46.64 & 60.68 & 0.06 & 0.8741 \\
\hline & $\mathrm{GP}, \mathrm{kg}$ & $7.47^{b}$ & $8.37^{a}$ & 0.11 & 0.0127 \\
\hline \multirow{4}{*}{$49-63$} & GMD, $g$ & $498^{b}$ & $558^{a}$ & 0.21 & 0.0012 \\
\hline & CA & 2.00 & 1.79 & 0.01 & 0.9421 \\
\hline & EA, \% & 49.80 & 55.80 & 0.12 & 0.6521 \\
\hline & $\mathrm{GP}, \mathrm{kg}$ & 5.99 & 6.33 & 0.13 & 0.6125 \\
\hline \multirow{4}{*}{$64-73$} & GMD, g & 599 & 633 & 0.02 & 0.5621 \\
\hline & CA & 1.96 & 1.86 & 0.12 & 0.0024 \\
\hline & $E A, \%$ & $50.76^{b}$ & $53.64^{a}$ & 0.21 & 0.0214 \\
\hline & $\mathrm{PV}, \mathrm{kg}$ & $18.6^{b}$ & $21.4^{\mathrm{a}}$ & 0.02 & 0.0012 \\
\hline \multirow{3}{*}{$33-73$} & GMD, g & $465^{b}$ & $535^{a}$ & 0.12 & 0.0121 \\
\hline & CA & $2.61^{b}$ & $1.83^{a}$ & 0.06 & 0.0011 \\
\hline & $E A, \%$ & $45.2^{b}$ & $57.3^{\mathrm{a}}$ & 0.01 & 0.0024 \\
\hline
\end{tabular}

a,b Medias con superíndices diferentes en la misma fila difieren $p<0,05$ (Duncan, 1955). T1, dieta sin aditivo microbiano. T2, dieta basal más $L$ acidophillus. d, días. GP, ganancia de peso. GMD, ganancia media diaria. CA, conversión alimenticia (consumo de alimento / GP). EA, eficiencia alimenticia (GP / consumo de alimento x 100) 
CA fue menor $(p<0.05)$ en el T2 a los 48 y 63 días de edad frente a T1. La EA mostró diferencia $(p<0.05)$ entre los tratamientos (T1 y T2).

No hubo diferencias entre tratamientos en la medición realizada en los últimos 10 días de estudio, para los indicadores productivos (GP, GMD y CA); sin embargo, la EA fue mayor ( $\mathrm{p}=0.0214$ ) en el T2 frente a los animales que no consumieron preparado microbiano (T1), (ver Tabla 2).

En la Tabla 3, se muestra el comportamiento de la incidencia de diarreas y la mortalidad del experimento I. Los trastornos diarreicos de los cerditos fueron mayores $(p<0.05)$ en los primeros 20 días después del destete en los animales del grupo control en comparación con los animales que consumieron preparado microbiano que contenía $L$. acidophilus. La incidencia de diarrea a partir de 49 días de edad hasta el final del estudio fue menor $(p<0.05)$ en el T2 con respecto a T1. En el tratamiento T2 no hubo muertes durante todo el estudio.

Tabla 3. Comportamiento productivo de los lechones que consumieron preparado microbiano, en el experimento I

\begin{tabular}{|c|c|c|c|c|c|}
\hline \multirow{2}{*}{ Edad, d } & \multirow{2}{*}{ Indicadores } & \multicolumn{2}{|c|}{ Tratamientos } & \multirow{2}{*}{ SEM } & \multirow{2}{*}{$\begin{array}{c}\text { Valor- } \\
\text { P }\end{array}$} \\
\hline & & T1 & T2 & & \\
\hline \multirow{2}{*}{$33-48$} & Incidencia de diarrea & $85.7^{a}$ & $28.5^{b}$ & 0.13 & 0.0241 \\
\hline & Mortalidad, \% & $14.2^{\mathrm{a}}$ & $0.00^{b}$ & 1.23 & 0.0175 \\
\hline \multirow{2}{*}{$49-63$} & Incidencia de diarrea & $57.1^{\mathrm{a}}$ & $5.33^{b}$ & 0.11 & 0.0273 \\
\hline & Mortalidad, \% & $14.2^{\mathrm{a}}$ & $0.00^{b}$ & 0.11 & 0.0123 \\
\hline \multirow{2}{*}{$64-73$} & Incidencia de diarrea & $14.2^{\mathrm{a}}$ & $0.00^{b}$ & 0.13 & 0.0022 \\
\hline & Mortalidad, \% & 0.00 & 0.00 & 3.01 & 0.0012 \\
\hline
\end{tabular}

\subsection{Experimento II}

En la Tabla 4, se observa el comportamiento productivo de los lechones al suplementar aditivo microbiano en la dieta basal. En las mediciones realizadas a los 65 días de edad, la GP y GMD fueron mayores $(p<0.05)$ en los grupos que fueron tratados con los preparados microbianos (T2 y T3) y de estos, en el T3 fue mayor $(p<0.05)$ frente a los demás grupos. Los animales del grupo T3, con 85 y 115 días de edad, obtuvieron mayor ganancia de peso $(p<0.05)$, con respecto a los demás, sin diferencias entre estos últimos.

La CA fue menor $(p<0.05)$ en el T3 frente a los animales del grupo T1 y T2, sin diferencias entre estos últimos en las mediciones realizados a los 85 y 115 días de edad. En cuanto a la EA fue mayor $(\mathrm{p}<0.05)$ en los animales que consumieron bacterias lácticas y levaduras en sus dietas, frente a los tratamientos T1 y T2.

Los trastornos diarreicos fueron mayores $(p<0,05)$ en el T1 frente a T2 y T3, a partir de 45 a 85 días de edad. En los cerdos que consumieron los aditivos microbianos no se presentaron trastornos diarreicos a partir de 86-115 días de edad, con respecto a T1. No se registraron animales muertos durante el estudio en el grupo T2 y T3. No fue así en el grupo de control T1 (Tabla 5).

\section{Discusión}

\subsection{Experimento I}

Los resultados obtenidos en cuanto a los parámetros productivos de los lechones destetados en el presente estudio (Tabla 2) se dieron posiblemente a la acción del $L$. acidophilus, debido a que estos organismos ayudan a mejorar en los procesos de digestión y absorción de los nutrientes, permitiéndoles realizar un mejor aprovechamiento de sus nutrimentos, en efecto favorece al aumento de ganancia de peso del animal, resultado 
observado en el presente estudio, al lograr un mejor comportamiento productivo en los cerdos.

Tabla 4. Comportamiento productivo de los lechones que consumieron los preparados microbianos, en el experimento II

\begin{tabular}{|c|c|c|c|c|c|c|}
\hline \multirow{2}{*}{ Edad, d } & \multirow{2}{*}{ Indicadores } & \multicolumn{3}{|c|}{ Tratamientos } & \multirow{2}{*}{ SEM } & \multirow{2}{*}{ valor-P } \\
\hline & & T1 & T2 & T3 & & \\
\hline \multirow[t]{2}{*}{ Inicio (45 d) } & $\mathrm{PV}, \mathrm{kg}$ & 13.55 & 13.45 & 13.51 & 0.01 & 0.8412 \\
\hline & $\mathrm{PV}, \mathrm{kg}$ & $10.86^{c}$ & $11.70^{\mathrm{b}}$ & $12.84^{a}$ & 0.13 & 0.0241 \\
\hline \multirow{4}{*}{$45-65$} & GMD, g & $500^{c}$ & $585^{b}$ & $642^{a}$ & 0.10 & 0.0011 \\
\hline & $\mathrm{CA}$ & $1.88^{a}$ & $1.75^{\mathrm{a}}$ & $1.59^{b}$ & 0.01 & 0.0021 \\
\hline & $E A, \%$ & $52.9^{c}$ & $57.1^{\mathrm{b}}$ & $62.6^{a}$ & 0.11 & 0.0125 \\
\hline & $\mathrm{PV}, \mathrm{kg}$ & $14.49^{b}$ & $14.66^{b}$ & $15.96^{a}$ & 0.11 & 0.0127 \\
\hline \multirow{4}{*}{$66-85$} & GMD, g & $724^{b}$ & $733^{b}$ & $798^{a}$ & 1.21 & 0.0012 \\
\hline & $\mathrm{CA}$ & $2.00^{a}$ & $1.98^{\mathrm{a}}$ & $1.82^{\mathrm{b}}$ & 0.01 & 0.0012 \\
\hline & $E A$, & $49.8^{b}$ & $50.3^{b}$ & $54.8^{a}$ & 0.02 & 0.0011 \\
\hline & $\mathrm{PV}, \mathrm{kg}$ & 15.90 & 16.14 & 16.29 & 0,13 & 0.8125 \\
\hline \multirow{4}{*}{$86-105$} & GMD, g & 795 & 807 & 814 & 0.02 & 0.5621 \\
\hline & $\mathrm{CA}$ & 2.5 & 2.5 & 2.4 & 0.12 & 0.8124 \\
\hline & $E A$ & 39.4 & 40.1 & 40.3 & 0.21 & 0.9214 \\
\hline & $\mathrm{PV}, \mathrm{kg}$ & $7.84^{\mathrm{b}}$ & $8.10^{\mathrm{b}}$ & $9.20^{\mathrm{a}}$ & 0.06 & $<.0001$ \\
\hline \multirow{3}{*}{$106-115$} & GMD, g & $784^{b}$ & $810^{b}$ & $920^{a}$ & 0.03 & 0.0021 \\
\hline & $\mathrm{CA}$ & $3.0^{\mathrm{a}}$ & $2.9^{b}$ & $2.5^{b}$ & 0.01 & 0.0125 \\
\hline & $E A, \%$ & $33.2^{b}$ & $34.3^{b}$ & $39.0^{a}$ & 0.01 & 0.0110 \\
\hline \multirow{4}{*}{$45-115$} & $\mathrm{PV}, \mathrm{kg}$ & $49.09 c$ & $50.6^{b}$ & $54.30^{a}$ & 0.01 & 0.0127 \\
\hline & GMD, $g$ & $701^{b}$ & $722^{b}$ & $775^{a}$ & 0.02 & 0.0012 \\
\hline & $\mathrm{CA}$ & 2.16 & 2.15 & 2.00 & 0.01 & 0.0751 \\
\hline & EA, \% & $45.1^{c}$ & $46.4^{b}$ & $49.8^{a}$ & 0.02 & 0.0021 \\
\hline
\end{tabular}

a,b Medias con superíndices diferentes en la misma fila difieren $\mathrm{p}<0,05$ (Duncan, 1955). T1, dieta sin aditivo microbiano. T2, dieta basal más $L$. acidophilus. T3, dieta basal más $L$. acidophilus más $K$. fragilis (L-4 UCLV) d, días. GP, ganancia de peso. GMD, ganancia media diaria. CA, conversión alimenticia (consumo de alimento / GP). EA, eficiencia alimenticia (GP / consumo de alimento x 100)

Tabla 5. Comportamiento productivo de los lechones que consumieron preparado microbiano, en el experimento II

\begin{tabular}{llccccc}
\hline \multirow{2}{*}{ Edad, d } & \multirow{2}{*}{ Indicadores } & \multicolumn{3}{c}{ Tratamientos } & \multirow{2}{*}{ SEM } & \multirow{2}{*}{ Valor-P } \\
\cline { 3 - 5 } & & T1 & T2 & T3 & & \\
\hline \multirow{2}{*}{$45-65$} & Incidencia de diarrea & $46.5^{\mathrm{a}}$ & $6.6^{\mathrm{b}}$ & $6.6^{\mathrm{b}}$ & 0.13 & 0.0125 \\
& Mortalidad, \% & $13.3^{\mathrm{a}}$ & 0.00 & 0.00 & 1.23 & 0.0175 \\
\multirow{2}{*}{$66-85$} & Incidencia de diarrea & $33.3^{\mathrm{a}}$ & 0.00 & 0.00 & 0.11 & 0.0273 \\
& Mortalidad, \% & 0.0 & 0.00 & 0.00 & 0.11 & 0.9123 \\
\multirow{2}{*}{$86-105$} & Incidencia de diarrea & $20.0^{\mathrm{a}}$ & 0.00 & 0.00 & 0.13 & 0.0022 \\
& Mortalidad, \% & $6.6^{\mathrm{a}}$ & 0.00 & 0.00 & 0.01 & 0.0012 \\
\multirow{2}{*}{$105-115$} & Incidencia de diarrea & $13.3^{\mathrm{a}}$ & 0.00 & 0.00 & 0.06 & 0.0012 \\
& Mortalidad, \% & 0.00 & 0.00 & 0.00 & 0.01 & 0.1254 \\
\hline a,b Medias con superíndices diferentes en la misma fila difieren p< 0,05 (Duncan, 1955). T1, dieta sin \\
aditivo microbiano. T2, dieta basal más L. acidophilus. T3, dieta basal más L. acidophilus más K. fragilis \\
(L-4 UCLV) d, días
\end{tabular}

Similares resultados fueron reportados por Ayala et al. (2015), al adicionar probiótico obtenido a partir de las bacterias lácticas en las raciones de los cerdos jóvenes. El efecto también fue visto por Miranda et al. (2017) cuando adicionaron cultivo mixto de bacterias y levaduras en la dieta de los cerdos destetados. Brea et al., (2014) observaron mejorar la ganancia de peso y la salud al aplicar bacterias ácido lácticas ( $L$. acidophilus y $L$. rhamnosus). Sin embargo, Liu et al. (2013) al emplear Bacillus subtilis no encontraron diferencias en los parámetros productivos. Mientras, Tabasum et al. (2010) observaron un ligero aumento de peso, al suplementar levaduras en la dieta, haciéndose entender que los preparados microbianos a partir de bacterias ácido lácticas, mejoran la salud del animal en 
efecto a esto, reduce la conversión alimenticia y la eficiencia alimenticia es mayor (Brea et al., 2014; Sun et al., 2015).

La menor presencia de diarreas y muertes en los animales que consumieron preparado microbiano (Tabla 3) podría estar relacionada con el mejoramiento del sistema inmune, lo cual ayudó a inhibir de la liberación de agentes patógenos, al mejorar la barrera protectora en el tracto gastrointestinal, proceso que inhibe las funciones celulares de algunos agentes patógenos ( $E$. coli, clostridium y Salmonella) que afectan a la salud del huésped. En este sentido, (Ayala, 2015) reportó que las bacterias acido lácticas tienen la capacidad de producir sustancias antimicrobianas, como son las bacteriocinas y los ácidos orgánicos. Efectos que también fueron reportados por Pajarilla et al. (2014) quienes al suplementar aditivos microbianos a los cerdos redujeron en un $30 \%$ los trastornos diarreicos y muerte en los días posteriores al destete. Mientras que Ihara et al. (2013) reportaron controlar diarreas causada por la Salmonella spp., en lechones destetados. Jurado et al. (2013) observaron una ligera disminución de agentes patógenos en el lumen intestinal al incluir Lactobacillus spp., en la dieta de los cerdos.

Sun et al. (2015) al introducir microorganismos vivos como aditivos en la dieta de los animales modificaron la composición de la microbiota natural del huésped, estos cambios ocurridos a nivel intestinal afectaron positivamente en la digestión y absorción de nutrientes, vitaminas y minerales. Por su parte, Gaggìa et al. (2015) reportaron la competencia de los microorganismos probióticos por los sitios de adherencia para interaccionar entre sí, y al constituirse una población relativamente estable, actúa mejorando la microbiota natural del intestino en el huésped, frente a los cambios dietéticos o ambientales que son sometidos los lechones al destete (Etleva et al., 2010).

\subsection{Experimento II}

Los resultados en cuanto a los parámetros productivos de los cerdos en las etapas preceba e inicio de ceba (Tabla 4) probablemente fueron relacionados con la acción de los microorganismos empleados en el estudio y esto contribuyó a la mayor asimilación de los nutrientes, lo cual provocó la mejora en la conversión alimenticia y la eficiencia alimenticia; al mismo tiempo pudo actuar en la regeneración de las microvellosidades atrofiadas (Brea et al., 2014). Díaz et al. (2013), reportaron que las levaduras podrían actuar de manera simbiótica con las bacterias. También, se ha visto que algunas especies de levaduras logran hidrolizar a las disacaridasas e inducen a los efectos antiadhesivos y antagonistas frente a los agentes patógenos; como consecuencia a lo anterior mejora los indicadores productivos (lyer et al., 2010). Por su parte, Ciro et al. (2015) además del incremento en la ganancia de peso, ganancia media diaria, y la conversión alimenticia, observaron también mejorar la salud cuando los lechones fueron tratados con los probióticos, reportes que confirman que los microorganismos probióticos actúan como promotores del crecimiento de los cerdos en las diferentes etapas productivas. Similares valores fueron reportados por Rondón et al., (2015) cuando incluyeron bacterias lácticas desarrolladas en subproductos de la agroindustria en la dieta basal de los cerdos en la etapa inicio de ceba. Etleva et al., (2010) observaron mejorar la ganancia de peso, pero sin hallar diferencia en la conversión alimenticia, al aplicar $1.5 \mathrm{~mL}$ de probiótico que contenía Lactobacillus y Enterococcus faecium. Efecto que también fue reportado por Farzan et al. (1993) y Díaz et al. (2013) al adicionar preparados microbianos en la dieta de los cerdos en la etapa inicio de ceba.

Los animales que consumieron los preparados microbianos ( Tabla 5) lograron reducir la incidencia de diarreas, probablemente debido a la acción bactericida de los microorganismos probióticos ( $L$. acidophilus y $K$. fragilis (L-4 UCLV)) empleados en la dieta de los cerdos en estudio. En este sentido, Campbell et al. (2013) y Rondón et al. (2013) plantean que el efecto benéfico de los probióticos se produce cuando la dosis administrada es adecuada. Esto a su vez, genera un mejor balance microbiano en el huésped, como resultado a lo anterior mejora la salud y el estado inmunológico del animal (Miranda et al., 
2017). Criterios que comparten otros autores, (Liu et al., 2013 y Ciro et al., 2015) en estudios realizados con cerdos en las diferentes etapas productivas.

Tabasum et al., (2014) plantea que la utilización de bacterias ácido-lácticas disminuye la incidencia de diarreas en cerdos causados por la E. coli y Salmonella spp. Los resultados concuerdan con los reportados por Díaz et al., (2013), quienes demostraron la capacidad probiótica de los cultivos microbianos obtenidos a partir de bacterias ácido lácticas y levaduras fermentadas en subproductos de la agroindustria. Por su parte, Ihara et al., (2013) reportaron la producción de ácidos orgánicos en el tracto gastrointestinal, y estos variaron los valores de $\mathrm{pH}$, cuando los cerditos consumieron probióticos.

Mientras que, Liu et al., (2013) reportaron la acción de los microorganismos probióticos frente a los agentes patógenos, esto controló los trastornos diarreicos en cerdos destetados. Reportes de Betscher et al., (2010) coinciden en parte con los resultados obtenidos en el presente estudio, lo cual ratifica el efecto benéfico de los preparados microbianos sobre la salud y los parámetros productivos.

\section{Conclusiones y recomendaciones}

En las condiciones del presente estudio, el empleo de los preparados microbianos en los cerdos mejora la ganancia de peso, ganancia media diaria y eficiencia alimenticia en las etapas del destete, crecimiento e inicio de ceba. tratados.

Asimismo, se logra controlar la incidencia de diarreas y la mortalidad en los animales

Los animales que consumieron el cultivo mixto de bacterias lácticas y levaduras, fueron los que mejor comportamiento productivo y de salud tuvieron.

\section{Bibliografía}

Ayala, L., Bocourt, R., Castro, M., Dihigo, L. E., Milián, G., Herrera, M., y Ly, J. (2012). "Desarrollo de órganos digestivos en cerditos descendientes de madres que consumieron un probiótico, antes del parto y durante la lactancia". Revista Cubana de Ciencia Agrícola, 48(2), 133-136.

Betscher, S., Beineke, A., Schönfeld, L., y Kamphues, L. (2010). "Effects of diet's physical form (grinding intensity; meal/pellets) on morphological and histological parameters (eg ratio of neutral to acid mucins) of the gastrointestinal tract in weaned piglets". Livestock Science, 134, 149-151.

Brea, O., Ortiz, A., Elías, A., Herrera, F., y Motta, W. (2014). "Utilización de la harina de frutos del árbol del pan (Artocarpus altilis), fermentada en estado sólido, en dietas destinadas a cerdos en preceba". Revista Cubana de Ciencia Agrícola, 48(4), 391398.

Campbell, J.M., Crenshaw, J.D., \& Polo, J. (2013). "The biological stress of early weaned piglets". Journal of Animal Science and Biotechnology, 4(1):19.

Ciro, J.A., López, A., y Parra, J. (2015). "La adición de cepas probióticas modula la secreción de mucinas intestinales en íleon de cerdos en crecimiento". Revista CES Medicina Veterinaria y Zootecnia, 10(2): 150-159.

Díaz, B., Elías, A., \& Valiño, E. (2013). Nutritional and economical efficiency of three biosilages from agroindustrial wastes in beef cattle. Cuban Journal Agriculture Science, 47(2): 143-150.

Duncan, D.B. (1955). "Multiple range and multiple F test". Biometric, 11(1):1-42.

Etleva, V.D., Thanas, P., Pashk, L., \& Myqerem, T. (2010). "Using combined probiotic to improve growth performance of weaned piglets on extensive farm conditions". Livestock Science, 134(3): 249-251.

FAO. 2016. "Probiotics in animal nutrition - Production, impact and regulation by Yadav S. Bajagai", Athol V. Klieve, Peter J. Dart and Wayne L. Bryden. Editor Harinder P.S. Makkar. FAO Animal Production and Health Paper No. 179. Rome. 
Farzan, A., Kircanski, J., DeLay, J., Soltes, G., Songer, J.G., Friendship, R., \& Prescott, J.F. (2013). "An investigation into the association between cpb2-encoding Clostridium perfringens type A and diarrhea in neonatal piglets". Canadian Journal of Veterinary Research, 77(1):45-53.

Gaggia, F., Mattarelli, P., \& Biavati, B. (2010). "Probiotics and prebiotics in animal feeding for safe food production". International Journal of Food Microbiology, 141(31) 515528.

Ihara, Y., Hyodo, H., Sukegawa, S., Murakami, H., \& Morimatsu, F. (2013). "Isolation, characterization, and effect of administration in vivo, a novel probiotic strain from pig feces". Journal animal of Science, 84:434-441.

Iyer, R., Tomar, S., Umamaheswari, T., \& Singh, R. (2010). "Streptococcus thermophilus: a multifunctional lactic acid bacterium". International Dairy Journal, 20(3):133-141.

Jurado. H., Ramírez, C., y Martínez, J. (2013). "Evaluación in vivo de Lactobacillus plantarum como alternativa al uso de antibióticos en lechones". Revista MVZ Córdoba, 18(supl): 3648-3657.

Liu, F., Li, G., Wen, K., Wu, S., Zhang, Y., Bui, T., Yang, X., Kocher, J., Sun, J., Jortner, B., \& Yuan, L. (2013). "Lactobacillus rhamnosus GG on rotavirus-induced injury of ileal epithelium in gnotobiotic pigs". Journal of pediatric gastroenterology and nutrition, 57(6):1-18.

Miranda, J., Marín, A., Baño, D., \& Hidalgo, L. (2017). Efecto de dos preparados probióticos sobre los parámetros productivos y la reducción de diarreas en cerdos pre y post destete. Aporte Santiaguino, 10(1):143-150.

Miranda-Yuquilema, J., Marin, A., \& Baño, D. (2017). "Elaboration of a bioprepared with probiotic effect from a mixed culture of lactic bacteria and yeasts". Bionatura, 2(1):245-247.

NRC. (2012). "Nutrient Requirements of Swine 11th Revised Edition". Washington, DC: National Academy of Sciences.

Pajarilla, E., Chae, J., Balolong, M., Kim, H., \& Kang, D. (2014). "Assessment of fecal bacterial diversity among healthy piglets during the weaning transition". The Journal of general and Applied Microbiology, 60(4):140-146.

Rondón, A., Ojito, Y., Arteaga, F., Laurencio, M., Milián, G., y Pérez, Y. (2013). "Efecto probiótico de Lactobacillus salivarius $\mathrm{C} 65$ en indicadores productivos y de salud de cerdos lactantes". Revista Cubana de Ciencia Agrícola, 47(4): 401-407.

Sun, Y., Park, I., Guo, J., Weaver, A., \& Woo, S. (2015). "Impacts of low level aflatoxin in feed and the use of modified yeast cell wall extract on growth and health of nursery pigs". Animal Nutrition, 1(3): 177-183.

Tabasum, S., Hoon, J., Mun, H., \& Yang, C. (2014). "Evaluation of Lactobacillus and Bacillus-based probiotics as alternatives to antibiotics in enteric microbial challenged weaned piglets". African Journal of Microbiology Research, 8(1):96-104. 